\title{
Critical Thinking, A Deflated Defense: A Critical Study of John E. McPeck's Teaching Critical Thinking: Dialogue and Dialectic ${ }^{1}$
}

\author{
JONATHAN E. ADLER Brooklyn College, CUNY
}

Key Words: Critical thinking (CT), liberal education, transfer (transferability; transfer of learning), argument analysis, informal logic.

Abstract: A critical study of McPeck's recent book, in which he strengthens and develops his arguments against teaching critical thinking (CT). Accepting McPeck's basic claim that there is no unitary skill of reasoning or thinking, I argue that his strictures on CT courses or programs do not follow. I set out what I consider the proper justification that programs in CT have to meet, and argue both that McPeck demands much more than is required, and also that it is plausible that this deflated justification can be met. Specifically, 1 argue that it is reasonable to expect transfer of learning for basic logical skills. Additional topics covered include: the relation of liberal education to critical thinking, argument analysis, testing for CT, and the value of conceptual or linguistic analysis.

\section{Overview}

In this brief collection of essays, most previously published, McPeck strengthens and develops the central arguments of his first book, Critical Thinking and Education (St. Martin's Press, 1981). The essays can be read separately, but read together, their central argument is more forceful. McPeck also reprints criticisms of his first book by Stephen Norris, Harvey Siegel, and Richard Paul followed by his replies to each. While the idea of including criticisms is good, I did not find these as helpful as they might have been had the critics diverged from McPeck at later, rather than the initial, stages of his argument. There is an index, but no bibliography - a regrettable absence even with the endnotes. (An oversight deserving correction is the failure to provide a bibliographic reference for Paul Hirst's work, in particular his article "Liberal Education and the Nature of Knowledge", 2 which is, as McPeck acknowledges, a pillar of his position. The same oversight occurs in the first book.) Minor errata were found: p. 5, last line; p. 8 , line 4.

Michael Scriven provides a foreword offering the expected praise without the fluff. He characterizes McPeck's importance to the critical thinking (CT) movement well:

John McPeck is the bookkeeper, the man who comes around to remind us of what we owe, according to the principles of our own sermon. (p. ix) ${ }^{3}$

More importantly, Scriven offers a practical proposal for responding to McPeck, whose substance l'll return to below.

Before beginning my critical study, an explanatory word. This study is very long, while McPeck's book is very short. At times, I treat at length arguments and claims that McPeck makes almost in passing - a few sentences, an aside, a footnote! There are four reasons for the gross imbalance. First, I am using my review of McPeck as a way of sketching a position on $\mathrm{CT}$ and informal logic that contrasts with McPeck's and some of those he criticizes. Second, my recurrent complaint is that McPeck fails to provide enough detailed cases and examples. His arguments owe too much of their plausibility to their abstract nature. To make this criticism stick, I must not follow his lead. Third, it is just a fact of intellectual and argumentative life that answering plausible objections, however brief, often requires a lengthy response. Fourth, as already suggested, I find much of the criticism of McPeck's work too dismissive. His work deserves critical scrutiny 
because many of his premises are important and right.

\section{The Central Argument and the Proper Justificatory Demand}

In both works, McPeck's central argument takes as its basic claim that there is no unitary skill of critical thinking, reasoning or, argument. Rather, the skills of critical thinking are always relative to particular content areas. But the critical thinking or thinking skills movement must assume that there is so unitary a skill to justify their courses and programs for improving thinking or reasoning. Consequently, since the basic assumption is false, these courses and programs are unwarranted. (p. xiv) If we want to improve $C T$, as we surely should, then the best approach is through reforming liberal education courses.

Accepting McPeck's basic claim that there is no unitary skill of reasoning or thinking, I will argue that his strictures on CT courses or programs do not follow. (I use "CT programs" and related phrases not to refer to any particular program, but as a shorthand for the most promising general thinking skills programs we find within the near future.) Rejecting McPeck's central argument and conclusion, however, does not imply a rejection of many of his points. In particular, he raises sensible doubts about the transferability of learning, and he properly defends the crucial role of a liberal education in promoting $\mathrm{CT}$. While both points are made in the earlier book, here he states his arguments and reasons more crisply and clearly.

An implicit corollary to McPeck's main claim-that CT programs and courses require a single underlying ability-is that what would justify those courses or programs is a demonstration that they can improve that ability. Since I accept McPeck's basic claim, but not his skeptical conclusions, I must reject this corollary concerning justification. To my way of thinking, it is inflated.
The following, I believe, captures the proper, deflated justification requirement: The material (including methods, skills, texts, topics) taught is (1) intellectually respectable, and (2) significantly improves upon students' learning either in other areas of study, or in important matters related to functioning as intelligent citizens. (3) The significant improvement remains once we discount for the content and areas of study that would have to be foregone, and (4) that improvement is largely due to the material taught being general (not essentially connected to any one knowledge or subject domain).

The deflated justification requirement is generic along two dimensions. First, although easiest to understand as applied to separate courses or programs, it is meant to cover various ways of teaching $\mathrm{CT}$. Besides separate courses, these include infusion into existing subject-matter, or mixtures of the two. ${ }^{4}$ Second, it applies to the justification not just of CT or informal logic courses, but any programs aimed at promoting general learning - thinking skills, writing, reading.

In general, those who defend CT programs tend to ignore or downplay the satisfaction of requirements (1) and (3); while those, like McPeck, who attack these programs, do the same for (2). (Requirement (4) must be satisfied if the gains are not to be the result of extraneous factors.) McPeck's inflation consists in demanding that $\mathrm{CT}$ programs be an educational Holy Grail, when all that should be demanded, and it is plenty, is that they promise to lead to the "significantly better." Improvement is what is required for justification, not some level of absolute success.

In this study, I attempt to render plausible the belief that the deflated justification requirement can be met, largely by clarifying what further investigation and research would and would not have to demonstrate. Merely articulating the proper requirement should itself go some ways toward allaying doubts due to acceptance of overly high standards and expectations. In particular, satisfying that requirement does not appear 
to demand a single underlying CT ability. Some claims to transferability, discussed below, must be made, but these should be in the spirit of cautious, testable conjectures, subject to empirical research.

In judging the plausibility that CT programs will meet (1)-(4), we should focus not on mass audience hype or inspirational pronouncements. Rather, we should focus on detailed course outlines, proposed texts, and specific curriculum proposals such as Scriven's:

\begin{abstract}
Our tasks, it seems to me, are; (i) to teach students how to use the English language's vast repertoire of logical terms ... . which they can use to improve their analysis of and communication about argument and presentation; (ii) to provide them with some simple devices and refinements of that vocabulary ...; ; and (iii) to bring all this to bear, not only on a thousand everyday examples, but on some of the great nonsubjects of our time, the concepts and topics-and practices - that have not yet become an official part of the general curriculum, but which demand the most rigorous intellectual consideration by every citizen.... (pp. ix-x)
\end{abstract}

When we focus on such specific, deflated, and worthy proposals, debate will start to move toward the narrowly circumscribed form of committee meetings, and away from the grandiose claims of books and journal articles. Differences among us will rest upon an enormous body of agreement concerning fundamental aims, methods, and subject-matter. For all the joys of debating relativism, transferability, and, that real thriller, the right definition of critical thinking, we will find ourselves engaged in the educationally more fruitful, if less momentous, task of determining how much time we can spend teaching (in, on, for) $X$, when we also want to do $Y$; whether we should use test $A, B$, or $C$ for purposes of assessment; and how we might reform a particular unit $Z$ toward stimulating more active learning. All the while, we will be highly conscious of the practical constraints operating in our educational setting.

\section{Public Relations and Diminishing Disagreement}

\author{
The book opens this way:
}

Every book or paper I have ever read, and every person I have ever asked, claims that the purpose of CT is, in one way or another, to improve people's reasoning ability about everyday problems and issues. (p. 3; see also p. 20)

McPeck proceeds to deny both that there is a unitary reasoning ability and that everyday problems and issues form a unitary object of thought or study. I agree. But need we read such a casual remark as having those implications? To think so is to demand too much from what is effectively a "sound bite."

In accusing McPeck of attacking a straw man, I am not claiming that the position he reports on has never been maintained. But a straw man remains a straw man even if real, and, indeed, pernicious. For McPeck claims to be challenging a position, not just some of its representatives. So his task can be fulfilled only if he represents that position well. On my view, he does not.

That McPeck is focusing on surface public relations, rather than the real justificatory demands for favoring courses and programs in CT and informal logic, arises elsewhere. Thus, after grudgingly admitting the value of one down-to-earth practical end served by CT courses and programs, McPeck responds:

But we should recognize that this is a rearguard action and not the vanguard of a new and promising curriculum for all. (p. 33)

The reply, notice, denies only that the proposal justifies a vanguard movement, not that it fails in itself. If one looks for vanguards, no doubt one will find simplistic overstatements. If we instead look at what is actually taught in courses in informal logic or CT, as revealed largely by the better textbooks, we will find much to admire, though little to make a revolution over. Such courses involve mainly study of various 
combinations of argument analysis, elementary formal logic, linguistic concepts relevant to argument including vagueness, ambiguity, speech acts, and conversational implicature, simple statistical, probabilistic, causal, and scientific reasoning, fallacies, and bias in reporting. The teaching of such content, which students may otherwise not receive, seems to me on the face of it of great value. Done well, it should fulfill the deflated justification.

Since I am conceding to McPeck that CT is not a unified ability and that everyday problems or issues do not form a natural class, my objections may not seem important. Does it really matter if McPeck attributes the justificatory belief that $X$ to the CT movement and $X$ is false, whereas I deny the attribution of $X$, though $I$ concur that it is false? Yes, it matters because McPeck infers from the falsity of $X$ to the lack of any justification for courses in CT and informal logic. But that conclusion follows only if $X$ is the only justification that can be offered. And that is what I deny.

Even McPeck finds less to question in the ideal of CT and in a range of educational implications drawn from that ideal than at first appears. Here are some points that McPeck endorses, which to my mind show far-reaching agreement with promoters of CT and informal logic programs:

(1) CT is a worthwhile aim of education.

(2) We can promote CT in students through modifying and altering the curriculum to demand more active, more engaged student intellectual participation.

(3) It is plausible to hold that CT courses or programs are especially valuable for remedial purposes. (pp. 33, 43)

(4) Much that we find in CT courses is valuable, and, in particular, "The standard academic discipline can profit considerably from much of the material in CT courses." (p. 13)

Indeed, after this last concession, McPeck adds defensively: "It might be fair to say that my disagreement with the standard approach to CT is largely pedagogic in character, but this difference, I contend, is significant." (p.13)

\section{CT and Age: A Point of Disagreement?}

\section{McPeck holds that}

it is unnecessary, and educationally premature, to teach CT to young children. (p. 43)

Here we come to a potentially sharp disagreement. Alas, upon reflection lines blur.

For one thing, McPeck is here using "CT" in an appropriately narrow, rather than in the popular, broad, ideological way. McPeck writes:

\footnotetext{
'CT' refers to a certain combination of what we might think of as a willingness, or disposition . . . together with the appropriate knowledge and skills, to engage in an activity or problem with reflective skepticism.... On those [rare] occasions [calling for CT] it is right and proper to start questioning some of our fundamental assumptions, or beliefs, and to try alternatives .... (p. 42, his italics)
}

Clearly, he is not referring to CT as a catchall for every thinking skill enumerable. ${ }^{5}$

Sticking to that narrower usage, McPeck is relying on arguments like E. D. Hirsch's $^{6}$ (pp. 39,44 ) as to the importance of gaining factual information about an issue before engaging in real criticism. It is in lower grades that we must provide the knowledge-base that will allow critical reflection to be responsible. McPeck rightly rejects the argument that if you do not teach directly for CT from the start, students in later years are going to be forever stuck with passive acceptance. (p. 43) 7

Yet, as I have mentioned, even this disagreement-concerning the grade level for introducing CT methods-diminishes in practical difference once we look at details. Consider replacing a textbook account of an important historical decision with a series of firsthand reports taken from a varied group of participants. Students are asked to decide what led to the decisionwhy did some arguments and reasons prevail? What assumptions did participants share? The attempt is to reconstruct the reasoning for purposes of understanding and evaluation, given different first-hand per- 
spectives, rather than relying on a single homogenized presentation. The attempt requires careful critical comparison among overlapping accounts. Students learn how biases and beliefs can influence judgments, even factual or perceptual ones, and how shared assumptions may constrain vision. That exercise and approach is fundamental to thinking critically about historical matters, and quite valuable, with suitable modifications, for young students. (It is also part of the normal practice of historians, a fact both obvious and important. ${ }^{8}$ )

Would McPeck reject this exercise? If not, how much disagreement remains? That question cannot be answered until McPeck actually gets down to the specifics of the curriculum. But he doesn't. In fact, as already mentioned, one of my chief complaints about this book (as well as the previous one) is how little space is devoted to examining the actual content of programs, texts, and curricula proposals. We are offered terribly few examples as a basis for drawing our own conclusions. My conjecture is that the sketchy example just offered and numerous other modest proposals like it could be endorsed by McPeck (and, I expect, Hirsch too) for students at quite a young age. ${ }^{9}$

\section{Transferability: The Evidence and the Facility Argument}

McPeck's most important arguments deny that thinking skills are transferable. The issue is central to Chapter 1, "What Kind of Knowledge Will Transfer?", though relevant empirical studies are mentioned in Chapter 4, "Some Practical Guidelines for Teaching CT". He represents the "standard

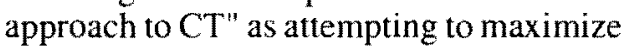
transfer by providing students with the general skills for using these logical principles whenever they are needed. (p. 13) Correlatively, he takes their argument against a "knowledge and information" approach to be that it minimizes transfer, since the skills are parochial to the area, and that one cannot predict what knowledge and information an individual may need for the future. (p. 13)

On McPeck's view, to the contrary, knowledge and information of fields or disciplines offers maximal transfer to "multiple problem domains." Standard CT skills approaches, by contrast, lead to minimal transferability due to a classic trade-off of depth for scope.

The study that McPeck finds most supportive of his conclusions concerning transferability is a 1984 review of research by Robert Glaser. ${ }^{10}$ I have surrounding me a number of recent articles which all are cautiously optimistic about the viability and value of thinking skills programs. A number of these explicitly endorse Glaser's conclusion that

Learning and reasoning skills develop not as abstract mechanisms of heuristic search and memory processing. Rather, they develop as the content and concepts of a knowledge domain are attained in learning situations that constrain this knowledge to serve certain purposes and goals."

Thus, the distinguished educational psychologist Lauren Resnick in a report to the National Research Council concludes: ${ }^{12}$

\footnotetext{
The evidence shows clearly that thinking is driven by and supported by knowledge, in the form of both specific facts and organizing principles. This knowledge, together with the automated recognition and performance that come with extended practice, allows experts in any field to engage in more sophisticated thinking than people new to the field. At the same time, many aspects of thinking are shared across fields of expertise. These include a wide range of oral and written communication skills, mathematization and representational abilities, principles of reasoning, and skills of argument construction and evaluation. These can be thought of as 'enabling skills' for learning and thinking. ${ }^{33}$
}

And her next conclusion, subsequently to be slightly qualified, is that

Elements of thinking are clearly teachable..$^{4}$ 
The state of evidence concerning transfer from cognitive educational psychology is one of very cautious optimism. Though mixed, experimental results tilt toward transferability, all respectful of Glaser's conclusion. Everyone favors further research and analysis. ${ }^{15}$

Let us make a simple distinction between horizontal transfer and vertical transfer. Horizontal transfer is transfer between fields or disciplines; vertical transfer is transfer in depth or complexity. In these terms, McPeck's important claim is that courses or programs in CT realize extensive horizontal transfer at the cost of vertical transfer. The exercises and examples in most of the textbooks I know lend credibility to McPeck's claim. In general, the materials that students use to develop their skills are much less intellectually challenging than the material in the standard curriculum. ${ }^{16}$ That gap leads one to suspect promises of extensive vertical transferability from courses which rely heavily on these texts.

While I am sympathetic then to this claim of McPeck's, I treat it as tentative, in accordance with my (survey) evidence being limited and (hopefully) transitory. McPeck looks less to empirical evidence, and more to a priori reasoning, and so characteristically comes to grander conclusions:

In its effort to maximize the number of areas to which its general principles apply, this approach perforce sacrifices genuine effectiveness in all of them. While its prescriptions are generally true, they are also hollow, more truistic, than true-for example: 'Make sure the conclusion follows,' 'Look out for tautologies,' 'Is a fallacy being committed?', 'Don't contradict yourself.' (p. 14)

As is too often the case McPeck's analysis stops where the hard work should begin. Consider the last claim: Increasingly general prescriptions become truistic. But even truisms are only unhelpfully truistic for those to whom they are self-evident. They are not self-evident to all. In discerning an argument the prescription to "Find the con- clusion first," while no doubt obvious to readers of this article, is not widely followed. Isn't it just common-sense, a faculty that McPeck rightly admires, that we should avoid denying the value of some sound prescription, until we know what help is needed by those to whom it is directed?

We cannot rest with this reply. It appears to concede a lot to McPeck's charge of teaching truisms. While as slogans these are truistic, there need be nothing superficial about the teaching or courses that could lie behind them. Rigorous courses can be constructed meeting the highest intellectual standards, and useful as CT programs, to study consistency, the slippery slope "fallacy," and similar notions (including falsifiability, explanation as distinguished from justification or description, bias in the news media, statistical fallacies in everyday reasoning). McPeck could also equally (and equally unfairly) mock these by reducing them to slogans.

While this is clearly not the place to construct such courses, it is the place to suggest an argument. The "facility argument" (in truth no more than an argument sketch) concludes that a weak transferability claim is sufficient for CT programs, and that it is reasonable to expect it to be satisfied.

The linchpin of the argument comes from reflection upon a pillar of all explanations in cognitive science. Cognitive systems are systems with great burdens but limited resources. They must greatly constrain their processing demands and economize. All the central terms we find in the vast cognitive science literature-schemas, chunking, heuristics, sacrificing, mental set-are to be understood in this light. They point toward the continuous efforts our systems take to lessen their cognitive burden, even if at some cost in accuracy. Thus, for example, our cognitive systems use heuristics, not algorithms, in processing information, for these, though less reliable than algorithms, are much more efficient. (Consider figuring out how many books are on one library floor: Do you count them or do lots of averaging and assuming? ${ }^{17}$ ) 
Given his heavy reliance upon the research findings from cognitive educational psychology, it is surprising that McPeck ignores this fundamental explanatory mechanism. Notice, in particular, how well it would support his view of CT as "reflective skepticism":

CT does not come into play on every occasion where rational thought is required, but only on those comparatively rare occasions where we suspect something is amiss .... (p. 42)

Now, in fact, the claim is right in spirit, but too strong as stated. It conflates the conditions for appropriate critical thinking with the conditions for a criticism's being appropriate. The latter, so it is often said, holds only when there is a genuine reason to doubt, rather than the criticisms merely reflecting skeptical angst. But one may properly engage in critical thinkingcareful questioning, and scrutiny of basic claims or arguments-merely out of intellectual curiosity, where nothing is, or is suspected of being, amiss. Yet the spirit of "reflective skepticism" is right from the point of view of cognitive burdens: Critical thinking is difficult and time-consuming, so it can only be engaged in occasionally. Good critical thinking chooses its moments wisely.

For just that reason, it will be the more valuable if we give students facility (ease) with thinking skills, which is a considerably lesser demand than that we find a unitary thinking ability or a single executive thinking skills manager. If thinking skills are many, then we can assume that their efficient use involves a serious cognitive burden. (McPeck appears to deny the antecedent, with his claim that there are few transferable skills. ${ }^{18}$ But his claim cannot be right. Just look at the lists of thinking skills in any source book on CT or thinking skills. ${ }^{19}$ ) It is plausible to believe that with extensive practice, these skills can become features of the students' cognitive repertoire, or their "know-how." In their normal, thoughtful activities - reading, reflection, writing - students will apply these skills intelligently, yet with barely a notice (hence, with barely any effort expended). ${ }^{20}$ In a word, logical analysis and related thinking skills will be the more used, and hence, more useful, as they become more effortless. Assuming that students don't think well, in part, because it is burdensome, cognitive science indicates that ease of access will lead to more likely use, and greater use, all other things equal, is better thinking.

That is the barest sketch and suggestion of an argument. But if the sketch and suggestion have any credibility, then it opens up a clear line of inquiry that does not need to accept any of the presuppositions that McPeck insists upon: an underlying CT ability, a unity of problems and content, etc. For the argument in full, many assumptions would have to be defended including that: we can discover the right skills and teaching methods; the skills taught correspond to the more frequent and important patterns in everyday and subject-matter use; practice with these skills will be reinforcing (one reason being, I believe, the Aristotelian one that thinking well (or virtuously) is more pleasurable); skills can become refined through intelligent, reflective practice; and ease of access leads to ease of application. ${ }^{21}$ Also, distinctions among these skills must be made. Few can ever reach the automaticity (or grace) of, say, the responses and reactions of the good squash player in action. Almost all must be applied with various degrees of control, intelligence, and knowledge. Still, if we take facility as a central (deflated) goal offered in response to contemporary complaints about students' education, our teaching should shift to greater emphasis on extensive and varied practice, and a focus on those skills that lend themselves to embedding as firm, well-honed dispositions.

Obviously, we want much more from critical thinkers, and no doubt much more has been claimed for CT programs. But what we must highlight first, and not lose sight of, are the minimal goals that would 
make such programs worthwhile, and caution critics.

\section{CT, Liberal Education, and Curriculum Reform}

In arguing for the value of liberal education, McPeck is careful to deny that his doubts about the transfer of general skills represents a skepticism about transfer, per se:

\begin{abstract}
The problem, then, is not whether specific knowledge and information can transfer, because careful reflection shows that it does, but rather, what knowledge and information will have the most transfer .... (p. 16)
\end{abstract}

The solution for McPeck is liberal education. McPeck moves from rejecting content-free thinking to the opposed horn of transferable but discipline-bound knowledge. Researchers find room between those two horns.

In a recent paper, Marilyn Jager Adams $^{22}$ reports upon a real educational program-"Odyssey" - which has displayed early and notable success in Venezuela, especially with children from disadvantaged backgrounds. Adams accepts Glaser's conclusion that differences in knowledge account for differences in performance across a wide variety of comparisons (e.g. experts and novices; high and low scorers on aptitude tests), ${ }^{23}$ and she casts doubts on the usual evidence cited in support of transfer:

significant gains ... show up only on tests that are highly similar to the curricula in content and structure. ${ }^{24}$

Now this should please McPeck, but Adams does not draw any skeptical conclusions about the possibility of teaching thinking. Quite the contrary. The key is that transfer is maximized through well-chosen content, but not through the conventional content areas. There should be courses in thinking and they should be "content-rich" because "the more you know, the more you learn." The content must be accessible and varied, and the skills and principles taught explic- itly. The goal being - and preliminary findings are highly promising-to maximize transfer.

As already mentioned, McPeck looks not to the kind of content-rich courses in thinking that Adams proposes, but to the traditional liberal arts curriculum. Liberal education is the best approach to $\mathrm{CT}$ because of the relevance of knowledge to transfer (especially, what I called "vertical transfer"):

regarding what particular knowledge is the richest and potentially most powerful ... I see no competitive substitute for a liberal education. In particular, I am talking about the rational perspective which comes from an informed study of natural and social sciences, together with history, mathematics, literature, and art .... (p. 16)

Although I believe McPeck is hasty in treating this view as being in irremediable conflict with CT programs, he is right to emphasize the role of liberal education in developing critical thinkers. Its neglect in articles promoting thinking skills is a kind of antiintellectualism-skills over substance; instrumental over intrinsic value; breadth over depth. The relevance of the substance and methods of philosophical inquiry and analysis, in particular, is largely avoided in the CT movement, despite the fact that most members are trained in philosophy. ${ }^{25}$ The reason is, I presume, to avoid chauvinism. Fear of that accusation and an ecumenical spirit do not justify the timidity.

To mention only one example of the value of philosophy itself in promoting CT, consider McPeck's (and Harvey Siegel's ${ }^{26}$ ) valuable reference to an epistemological approach that focuses on "philosophies-of" as a basis for questioning fundamental assumptions in different fields. Both send us to Israel Scheffler's ${ }^{27}$ discussion of a course for teachers, in which he relates to education certain central concepts from epistemology and the philosophy of science. The main assignment attempts to 
acquaint each student with "philosophical literature bearing on the foundations of his own teaching subject."28 Scheffler comments:

To my great surprise, I found that the typical student had been simply unaware of the existence of a serious philosophical literature relating to his teaching subject... many students soon reported their delight at finding a new and fundamental source of insight into materials with which they would presently be working as teachers. ${ }^{29}$

In referring us to suggestions like Scheffler's, McPeck shows himself to be, though a champion of liberal education, not an uncritical one. Aside from a pedagogy that tries to stimulate more active learning, McPeck wants to reorient liberal education, as already mentioned, toward concern with its epistemological and philosophical roots:

\begin{abstract}
Mastery of these disciplines is too often measured in terms of how many 'facts' one has learned, and how proficient one has become in its 'method.' ... A plausible solution to this problem is to make the philosophy of $X$ and the philosophy of $Y$ an integral part of what it means to 'learn $X$ ' or to 'learn Y.' (p. 17)
\end{abstract}

Yet we know that in their actual workings the disciplines tend to be highly conservative. As a practical matter the most effective way to accomplish McPeck's goal may be through courses in CT. Since those courses are new, not yet controlled by the disciplines, and have maximal transfer as an avowed goal, they may be able to resist the highly specialized, well-defined content with which most academics and teachers are comfortable.

But single, isolated courses are unlikely to realize the high level of critical thinking that many seek, especially among poorly prepared and motivated students. If the facility argument is correct (but certainly not "only if"), the (varied) practice, modeling, and instruction necessary to gain real facility with these skills is extensive, so then, arguably, it will be realizable only when it is done "across-the-curriculum."
The re-orientation may have to go much further than piecemeal curriculum restructuring toward more engaged learningsuch as proposals for more loosely structured, non-disciplinarily restricted, problem solving tasks for group work. ${ }^{30}$

Consider how far-reaching, and thus unlikely to be realized, the following proposal is despite its resting upon assumptions consonant with liberal education: Science should be to taught more like the humanities in the use of original texts. The patterns of reasoning to be sought will then be deeply and realistically embedded, not at all transparent, so that the crucial task for (vertical) transfer of extracting them is not by-passed. Also, in an historically sensitive approach, the actual struggles of reason during theory change are not whitewashed through the perspective of the current reigning doctrines. ${ }^{31}$ Mathematics would take a more central place throughout the curriculum because of the close ties within it between content and reasoning, and because of its modeling the ideal of deductive proof, where each step is justified by explicit rules. (Teaching writing, reading, and now CT across the curriculum are widely promoted, but for mathematics we bend over backwards to present non-technical "physics for poets" courses.) The humanities and social sciences might have to be less pluralistic in selection of texts and subjects, looking more to works where arguments dominate and CT skills are most usefully illustrated. They will have to be more science-like in a concern with finding and critically examining testable claims, and with well-reasoned justification.

The emphasis on original texts is encouraged not only by the instrumental goal of improving vertical transfer of CT, but also as intrinsic to a prominent feature of traditional liberal education that McPeck neglects. Using P. H. Hirst as a guide, McPeck emphasizes the various knowledge domains-humanities, sciences and mathematics, social studies, and the arts. But he neglects a feature of liberal education which is now under attack: Liberal education is 
marked by a set of texts, and texts whose inclusion depends upon judgments of depth, breadth, and quality. What I want to emphasize about these texts is their enormous cross-disciplinary relevance. The significance of works such as Adam Smith's The Wealth of Nations, Galileo's Dialogues on Two Worlds, Aristotle's Nichomachean Ethics, or Plato's Republic is not restricted to any one discipline. The result of the high specialization in fields today means that students are less likely to address and learn from these kinds of works in their full multifaceted richness. One way to study these texts is as models of serious, imaginative, and broad-minded reasoning and argument directed at fundamental questions. ${ }^{32}$ After the necessary practice with simple cases, why couldn't these provide more of the substance or content of courses aimed at teaching the rudiments of logical reasoning?

\section{Testing for CT}

Both my down-to-earth and lofty goals for $\mathrm{CT}$ courses must be responsive to another important concern that McPeck has: testing for $\mathrm{CT}$.

In Chapter 5, "Problems of Evaluating Critical Thinking Programs", McPeck presses his claim that there is no unitary ability of CT to test. Indeed, the whole idea of empirical testing for CT involves conceptual error! McPeck cites some evidence against any general reasoning ability. He repeats objections to the Watson-Glaser CT appraisal and other tests. He does not provide any examples from these tests. (The first book provided a few).

One way to test for whether CT courses improve CT is to use a test like the WatsonGlaser. Aside from his specific doubts about the test, McPeck takes two authors to task for attempting to use that test as a basis for testing the value of philosophy for improving CT. He worries that that is to view philosophy as having only instrumental value. But liberal education, and its subjects, should be valued for their intrinsic worth. (p. 62)

One might well respond to McPeck that there is no incompatibility - a course of study can be of both intrinsic and instrumental value. ${ }^{33}$ Still, as a practical matter, such a study would have significant results only with large numbers of sections of students. It is hard to doubt that the result would be a distortion of just the kind McPeck worries about: teaching for the test, and judging philosophy as a whole for its impact on these tests. The use of the Watson-Glaser and related tests would however be less objectionable if they were used to assess students' overall progress, rather than their progress in particular courses.

But we cannot avoid direct assessment of CT courses and programs because-at this stage anyway - their justification must be largely instrumental. One way to "operationalize" the needed instrumental justification is to test whether students who go through these programs or courses do better in their other courses, as well as with close reading and analysis of selected texts from better newspapers' or magazines' editorials and columns. Such assessments, especially the former, can be fairly unobtrusive. Another kind of testing would compare a CT course with other service courses. Consider a one or two semester CT course with an emphasis on writing. How do the students in that class compare to those in the standard one or two semester composition courses, in writing essays in the disciplines ${ }^{34}$

There are dangers in testing, as many have noted. A specific one that worries me is related to both McPeck's concern about placing pressure on the liberal arts curriculum toward becoming merely a means to the promotion of CT skills, and the well-known one of judging what is valuable by what is easily tested. The danger is a misrepresentation of the potential value of a topic or skill. Consider formal logic, whose instrumental value for the bettering of thinking is challenged from virtually every direction. ${ }^{35}$

The most straightforward transferable value we would expect from it is to help 
students in understanding the logical connectives of English, particularly as used in arguments. They should be better able to follow complex deductive reasoning, and sort out valid from invalid arguments. In studies of students' grasp of the conditional, results are discouraging. Students' ability to handle conditional reasoning, and the Wason selection task, specifically, ${ }^{36}$ is not markedly improved through a study of propositional logic. Though philosophy students do well on the LSAT, it would not be surprising if only a small portion of their success in the deduction sections was to be explained by their training in formal logic. (For one reason, the search for a suitable algorithm for each problem, which maps onto the familiar algorithms of deductive logic, would take much too long under test conditions.)

Yet it seems to me that a substantial, but indirect, value remains, as mentioned above in discussing the role of mathematics. Deductive logic provides an ideal of a rigorously justified, explicit argument. Also, in the reconstruction of ordinary arguments where premises and assumptions are often unstated, it is a helpful heuristic to take the arguer's aim as being to offer a valid argument. Further, the distinction between validity and soundness, the analysis of consistency and tautology, and the reliance of truth tables on exhausting all possibilities seem to be of broad educational value. Finally, as a number of texts appreciate, many ordinary arguments have the structure of certain simple valid forms: modus ponens and tollens, reductios, disjunctive syllogism, and transivity or chain arguments. It is reasonable to assume, as the facility argument does, that mastery of these forms will lead to greater sensitivity to, and easier identification of, these patterns in ordinary use. These less direct (potential) benefits for improving thinking are largely ignored, in the usual charges, both philosophical and empirical, against deductive logic.

Extensive testing of proposals for improving CT are necessary, but must be handled extremely carefully. ${ }^{37}$

\section{Critique of Informal Logic: Argument Analysis}

Repeatedly, I have complained about the lack of specifics in McPeck's arguments. In Chapter 1 he questions the value of argument analysis and the study of fallacies, both pillars of informal logic. Here he offers specific arguments, although, once again, unfortunately, no detailed examples. Let's consider his criticisms of argument analysis.

He objects, first, that analyzing arguments constitutes a small fraction of an intelligent person's reasoning. But this objection is forceful only if one thinks that small fraction insignificant. Arguments are prominent not only in philosophy, but also in many other subjects. Arguments also feature prominently in editorials, newspaper columns, and letters to the editor. Now if argument analysis helped to improve understanding on any of these fronts, wouldn't that be value enough? Who needs to apply it to all everyday reasoning?

McPeck finds argument analysis of limited value for two other reasons:

(1) argument analysis is always an ex post facto reconstruction of past reasoning, positing neither alternatives nor hypotheses for future consideration; and (2) the major focus of argument analysis is to determine the validity of arguments, not the truth of premises or evidence. And the truth (of premises) is more difficult to determine, but unquestionably of more value in practical affairs. (p. 6)

The claim that argument analysis is ex post facto warrants the same reply as for the claim that it is only a "small fraction": If we can enhance students' grasp of a complex piece of real argument, I'll be quite satisfied. Taking a respectable argument-say, one of Berkeley's arguments for why a particular primary quality suffers the same relativity as do the secondary qualities- 
and clearly and simply reconstructing it is no mean achievement. Students attempt to express, order, and standardize the premises and conclusions, as well as to fill in missing assumptions. Anecdotal evidence suggests that occasionally we have all seen the benefit of this use of argument analysis as an explanatory tool. Students begin with a hopeless sense that understanding an argument is utterly beyond them. Once the tangled argument is brought out clearly through analysis or reconstruction, however, the pattern of reasoning stands forth. The crucial premises are more readily discernible. No one who has ever taught a hard argument by analyzing it systematically, finally to see the dawning of illumination on students' faces, could possibly belittle it.

Perhaps McPeck has low regard for argument analysis because he believes that its major aim is to test an argument's validity. Not so: the main purpose of argument analysis is just to understand the argument. Validity is one important dimension for assessing an argument, which may, as I have already noted, even serve as an ideal for reconstructing, and hence, understanding, the argument. But it remains only one feature of a much more challenging and complex task.

Moreover, even when restricted to determining the truth of premises, argument analysis is valuable. Finding out the truth of premises where this doesn't involve either common knowledge or extensive research, generally involves criticism. When we can represent a set of premises explicitly, we can determine which premises are more or less worth challenging. And our criticisms are the more valuable (informative) for being able to locate their target exactlypremise 3 , rather than $4 .{ }^{38}$ (This value fits McPeck's own emphasis on CT as "reflective skepticism." "The critical thinker, therefore, knows what and when it might be reasonable to question something." (p. 28))

McPeck's questioning of "assumption hunting" is puzzling, although he is right that there are severe difficulties in teaching it as a general method. For one thing, he rightly notes that finding unstated assumptions is often not a matter of filling in enthymemes, but of engaging in interpretation. (p. 8) He has two objections. First, to move from analysis to interpretation is to -invite subjectivism, stripping "argument analysis of its objective integrity." (p. 8) Second, assumptions are confused with presuppositions, which are valuable to find precisely because they do not involve the arguer's subjective state and if false, "the argument cannot be sound."

On the first objection, it seems to me the danger of promoting subjectivism is exactly what we should risk if we want to gain vertical transferability. For with serious material there is no alternative to interpretation. There are going to be alternative possible assumptions, and we do our best to impose constraints or tests-the principle of charity, generality, fidelity - that provide a solid basis to select between these. ${ }^{39}$ The mark of objectivity here is not that we can determine a uniquely correct interpretation, but that we can justifiably eliminate many competitors. Does a reasonable person need more to block the inference from meaning not being right on the surface to its being simply up for grabs?

The idea that assumptions are matters wholly of subjective beliefs prevents McPeck from recognizing one way in which argument analysis need not be, as he claims, ex post facto. To interpret an argument fairly, you sometimes have to propose alternative premises or conclusions. The arguer may have left some out, he may be mistaken about which premise his argument requires, and his explicit rendition may require clarification. In parallel with the distinction between speaker meaning and sentence (word) meaning, we must recognize a distinction between what an arguer assumes for his argument and what the argument assumes. An arguer can be wrong about what his argument requires, and his argument can make assumptions of which he is unaware. The arguer's subjective intent is only one of many important bits of evidence as to how his argument should be 
interpreted or reconstructed.

In any case, McPeck's argument is hard to follow. In a footnote, he illustrates his distinction between assumptions and presuppositions. It seems to come down to a distinction between what a linguistic contribution suggests and what it (logically) implies. A difficulty with his illustration is just that it is made only for statements; how it translates into a distinction for arguments is unclear. Are presuppositions defined for the argument as a whole? Or, are they defined for the premises as a whole, or, rather, individually?

Even if that distinction can be made good, McPeck's reasoning seems to involve the claim that the only relations between statements are either deductive or subjective (a matter of the arguer's intent). There is no reason to accept the assumption that those alternatives are exclusive and exhaustive, as a look at any number of debates shows. Thus, in a well-known exchange over IQ, inheritance, and meritocracy, Richard Herrnstein and Noam Chomsky ${ }^{40}$ dispute whether an assumption that Chomsky attributes to Herrnstein's argument is really necessary or required. But Chomsky is not claiming that Herrnstein's assumptionthat rewards in a healthy, moral society must be in transmittable wealth -is logically entailed by Herrnstein's overt premises nor is he making a psychological attribution to Herrnstein's intent. It is more like this: Here is the most plausible assumption without which the premises are radically inadequate to yield the conclusion. That form of inference is wholly natural and familiar, even if often difficult. (As an analogy, consider the process of recognizing and understanding a novel metaphor.)

\section{Conceptual Analysis}

At the end of the book, McPeck conjectures that the root of the differences between himself and the standard accounts is that he is a Wittgensteinian, whereas his critics aren't. He speaks of a lack of shared "paradigms." The difference he believes

helps to explain: (a) much of the deeper misunderstandings about my view; and (b) why my view seems to appear so a priori to some folks, ... (p. 115; see also his reply to Norris)

The second difference, (b), captures a view of his work that I share. Although the remark just quoted is an aside and plays no direct role in his arguments, it is indicative, I believe, of his underlying philosophical biases. On their own, these deserve critical scrutiny for they are widely shared, playing an influential role in contemporary intellectual life. In this penultimate section, I shall bring together my complaint about McPeck's lack of specifics with criticisms of his dependence upon conceptual analysis as a mode of argument and as a way of conceiving the issues.

Chapter 3 on "Teaching Critical Thinking Through the Disciplines" is an extended reflection on Wittgenstein's languagegame metaphor as a way of capturing the discontinuities between fields. McPeck clings to the idea that the disciplines represent different, though alterable, "forms of life." (p. 37)

It is surely true that you cannot, for example, criticize sociobiological accounts of human altruism at length without understanding the theory of inclusive fitness or kin selection. Still, not all criticism is like that. For some purposes of criticism, full immersion in different "forms of life" is not required. I understand almost nothing about the Islamic faith, let alone participate in their "forms of life." But if sects allow their spiritual leaders to encourage murdering an author for his novel's alleged insults to their religious beliefs, then I can criticize that sect, while remaining ignorant of its details. The reason is that, on the one hand, you cannot isolate any system of beliefs in active use from having some definite implications that we can grasp and assess across paradigms ${ }^{41}$ and on the other hand, my purposes in criticism may be just to find a good reason not to participate in your "forms of 
life."

Returning to McPeck's explanation for why he is misunderstood, he applies the idea of fundamental paradigm clashes in predictable ways:

Such deep-rooted differences cannot be resolved by simply cleaning up a few terms like warrant and ground, because these concepts have no equivalent meaning in the other paradigm. They are part of a different philosophical network. (p. 115)

This sounds perilously close to the all-purpose defense against objections: If you argue against me, you must hold to a different conceptual framework. Hence your objections are not really objections since what you affirm and I deny with the same words represent different meanings. That strategy or position will go down as the latter part of the 20 th century's contribution to the tradition of "poisoning the wells." 42

Perhaps, we are ultimately locked into different conceptual frameworks, unable, without distortion, to fairly state the views of those in a different conceptual prison. This breathtaking philosophical view need not be addressed to question its practical use. For in most real arguments, discussions, and inquiries we are far, far away from reaching breakdown. Indeed, even if you held this frameworks-as-prisons view, you should generally bracket it. It should be invoked, presuming you accept it, with the same reluctance, caution, and embarrassment one would have in abandoning a discussion because the participant has a speech defect.

In general, while this book relies less on conceptual arguments than his first, the influence remains. McPeck even repeats an egregious argument from the first work, although thankfully here it is given a less commanding role:

No matter how general or abstract the subject matter, if the thinking involved is not about some kind of $X$, then it is not describable as thinking at all. This consideration, then, binds thinking, and thus CT, to particular subjects or activities. (p. 20)
The argument faces a familiar dilemmatrue and uninteresting, or interesting and untrue. It is the former if no restrictions are placed on $X$; the latter, with such restrictions. The substitutions for $X$ that would satisfy the premise do not require that they be "particular subjects or activities," if as McPeck seems to require, that implies any coherence or unity in these subjects or activities, as would be the case in a discipline. For the premise will be true, if $X$ is any collection of things-thinking about the Morning Star, my daughter, the budget deficit, this argument, and my nagging headache. And that constitutes no particular subject or activity. In short, $X$ is ambiguous between merely being an object of a propositional attitude (its unrestricted use in the premise) and as a specific subject or set of subjects (its highly restricted use in the conclusion).

A final example of how McPeck's leaning toward conceptual analysis leads him astray is worth noting. Paul accuses McPeck of a "misleading representation" of the views of a number of writers, in particular, Robert Ennis. McPeck is obviously sensitive to this charge, noting that Ennis "does think that I have been unfair to his view." (p. 121) McPeck claims that there is no misrepresentation, but honest disagreement. His main evidence is that he fully quoted Ennis's own presentation.

That is not enough. True, he does not maliciously misrepresent, and, more pertinently, he provides the reader with the evidence to judge for himself whether there has been misrepresentation. But the misrepresentation remains. It involves a refusal to recognize, to be specific, that Ennis's exclusion of value judgments from the concept of critical thinking is due to Ennis's noble attempt to offer a working conception of critical thinking, one that is subject to experimental control. It is a basis for a research project, as the subtitle of his original article, as well as much of his subsequent investigations, makes clear, not a philosophical thesis. Consider what McPeck writes: 
Ennis's 'truncated concept' of critical thinking is not merely a benign deletion of something relatively unimportant, but a severe limitation prohibiting the use of critical thinking from the most straightforward cases requiring it. (p. 54)

But, as I see it, Ennis is not claiming, nor, more pertinently, does he need to claim, that values are unimportant, only that at this early stage they are not susceptible to rigorous experimental control. ${ }^{43}$

Why does McPeck go wrong here, even when so self-consciously trying to get rather simple matters right? It is no penchant for "poisoning the wells." McPeck always tries to be an honest, fair critic, as exemplified in his reprinting critiques of his view. He makes every effort to note points of agreement with those he is criticizing or challenging. His position is stated up front, and his arguments and criticisms are generally presented simply and clearly.

What may mislead him here, and what certainly misleads him elsewhere, is his leaning toward conceptual analysis and criticism. He strives for a priori arguments, where issues are empirical, and knockdown criticisms, where criteria for evalua- tion are too diverse and positions too fluid for definitive judgment. In so doing, he (sometimes) contorts the views he is criticizing so as to render them susceptible to his limited critical tools. Were he to take Ennis's proposal as an initial working list of manageable skills, within a broad, ongoing research project in which the conception is intended to (moderately) alter as study proceeds, his dismissive attitude couldn't be sustained. Not, at least, on the grounds he offers.

\section{Conclusion}

McPeck offers us a lively, well-written, provocative work. But he could offer us more. He has the right orientation toward liberal education, a healthy distance from the messianism starting to infect the CT movement, and the robust good commonsense intelligence to offer us a fair, thorough assessment of critical thinking, informal logic, and thinking skills programs. Next time I hope he will dare to write a more boring, pedantic book.

\section{Notes}

1 McPeck, John E. (1990). Teaching Critical Thinking: Dialogue and Dialectic. New York: Routledge, Chapman and Hall. Pp. xv, 135. I am grateful to John McPeck for helpful, restrained comments. Thanks also to Carol Caraway and Ralph Johnson for good editorial suggestions.

2 P. H. Hirst, "Liberal Education and the Nature of Knowledge", reprinted in R. S. Peters, ed., The Philosophy of Education, 87-111, Oxford University Press, 1973

3 All references are to Teaching Critical Thinking unless otherwise stated.

4 On these differences and their relevance to the transferability issue see Robert H. Ennis, "Critical Thinking and Subject Specificity: Clarification and Needed Research", Educational Researcher 18 (1989), 4-10.
5 For an example of using "CT" as a catch-all see Peter Facione, Critical Thinking: A Statement of Expert Consensus for Purposes of Educa. tional Assessment and Instruction, distributed by the American Philosophical Association, 1990.

6 E. D. Hirsch, Jr, Cultural Literacy: What Every American Needs to Know, Houghton Mifflin, 1987. See also Richard Rorty's "Education, Socialization, and Individuation", Liberal Education 75 (1989), 2-9.

7 Confusions between indoctrination and authoritarian or directive teaching obscure this point. See George Sher and William J. Bennett, "Moral Education and Indoctrination", in George Sher, ed., Moral Philosophy: Selected Readings, Harcourt Brace Jovanovich, 1987. 102-12. 
8 As a start, consider Richard E. Neustad and Emest R. May's study of the reasoning leading to the Bay of Pigs decision in Chapter 8 of their Thinking in Time: The Uses of History for Decision Makers, The Free Press, Macmillan, 1986; and Irving Janis's discussion of the same decision in his Victims of Groupthink, Houghton Mifflin, 1972. See also Robert J. Swartz; "Teaching for Thinking: A Developmental Model for the Infusion of Thinking Skills into Mainstream Instruction", preprint of article to appear in Joan Baron and Robert Sternberg, eds., Teaching Thinking: Theory into Practice, W. H. Freeman, 1986. A frequently made charge against Hirsch conflicts with my belief that he could accept an exercise like this one. The charge is that he intends his list of cultural literacy terms to be taught as a list. (See, for example, Ennis, op. cit., note 4, p. 6.) Although Hirsch places approving emphasis on memorization, he is not committed, and explicitly denies, that cultural literacy is to be achieved only through rote learning.

9 Age and level of preparation are relevant to how much emphasis should be placed on factual knowledge and how much upon critical analysis and debate. Throughout this paper, my comments and proposals are most naturally applicable to college students in their beginning years. I mean the claims to apply more broadly, modulo my overall leaning toward Hirsch and McPeck's view that critical analysis and thinking should be later emphases in schooling. See also Rorty, op. cit., note 6.

10 Robert Glaser, "Education and Thinking: The Role of Knowledge", American Psychologist, Vol. 39, No. 2, 93-104.

11 lbid., p. 99.

12 Lauren Resnick, Education and Learning to Think, National Academy Press, Washington, DC, 1987.

13 lbid, p. 46.

14 Ibid.

15 See Ennis's article cited above (note 4) and McPeck's reply, "Critical Thinking and Subject Specificity: A Reply to Ennis", followed by Ennis's response, "The Extent to Which Critical Thinking is Subject-Specific: Further Clarification", Educational Researcher 19, 10-12 (McPeck) and 13-16 (Ennis). Ennis's bibliography is helpful. Two especially illuminating articles are D. N. Perkins and Gavriel Salomon,
"Are Cognitive Skills Context-Bound?", Educational Researcher 1989, 16-25; and Richard E. Nisbett, Geoffrey T. Fong, Darrin R. Lehman, and Patricia W. Cheng, "Teaching Reasoning", Science 238 (1987), 625-31.

16 For a valuable exception, see Alec Fisher, The Logic of Real Arguments, Cambridge University Press, 1988.

17 In research on the teaching of writing these ideas are taken seriously, especially in the work of Linda Flower. See her essay with John Hayes, "The dynamies of composing: Making plans and juggling constraints", in L. W. Gregg and E. R. Steinberg, eds., Cognitive Processes in Writing, L. Erlbaum, 31-50.

18 See above, two quotations back, from McPeck p. 14 , and more recently, in his reply to Ennis, note 15 .

19 Even if these lists (see note 5) are greatly pruned, as they should be, what remains goes well beyond McPeck's list.

20 An argument of Richard Paul's against E. D. Hirsch's program of "cultural literacy" misses its target, precisely because Paul neglects the time and effort constraints in normal, even if careful and studious, reading. See Richard W. Paul, Critical Thinking: What Every Person Needs to Survive in a Rapidly Changing World, A. J. A. Binker, ed., Center for Critical Thinking and Moral Critique, Sonoma State University, 1990, 434-35.

21 McPeck takes the problem of a lack of use or application of learned skills as showing a lack of an "executive skill." (See his reply to Ennis, op. cit., note 15, p. 12.) No doubt this is so, but the suggestion that that is the only answer to the problem is in character with McPeck's setting unrealizable requirements, and then voicing skepticism when they are not satisfied.

22 "Thinking Skills Curricula: Their Promise and Progress", Educational Psychologist 24 (1989), 25-77.

23 Ibid., p. 42.

24 Ibid., p. 30.

25 A notable exception is Matthew Lipman in his writings and work through the Institute for the Advancement of Philosophy for Children. See also Gareth B. Matthews, Philosophy and the Young Child, Harvard University Press, 1980. 
Harvey Siegel, Educating Reason, Routledge, 1988.

27 Israel Scheffler, "Philosophies-of and the curriculum", in J. F. Doyle, ed, Educational Judgments: Papers in the Philosophy of Education, Routledge \& Kegan Paul, 1973.

proposals have been made along these lines. See, for example, Joseph Katz et al., A New Vitality in General Education, Association of American Colleges, 1988.

31 See Thomas Kuhn's criticisms and (unspirited) defense of the textbook tradition in science education in The Structure of Scientific Revolutions, 2nd edition, enlarged, University of Chicago Press, 1970. I take comfort in Kuhn's criticism of textbooks, but do not worry about his defense of them, because he explicitly restricts his defense to what is required for the training of scientists. I am concerned with the larger group who take introductory science without plans to continue much further. I read Kuhn's praise of the distortional quality of textbooks as ironic, solely a concession to the need to train scientists, and not at all a recommendation for how the history of science should be taught, when not for that specific end. For a harsher reading see Siegel, op. cit., note 26 , Chapter 6, section E.

32 For a work that could serve as a model for developing the kind of courses in CT that I am suggesting see M. Finocchiaro, Galileo and the Art of Reasoning, D. Reidel, 1980.

33 A response made by the authors. See D. B. and L. F. Annis, "McPeck on CT: A Reply", Informal Logic 6, 42-44.

34 If the views of the distinguished English teacher Wayne C. Booth are accepted, then the goals of composition courses sufficiently overlap those of informal logic courses as to allow meaningful comparisons. See his The Vocation of a Teacher, University of Chicago Press, 1988, especially essays 2,6 and 19 . I have drawn connections between informal logic and the teaching of writing in my "Alternatives, Writing and the Formulation of a Thesis", Informal Logic 9 , $71-80$.

35 In fact, questioning the value of deductive logic for the improvement of reasoning is where informal logic began.
36 For discussion and references, see the article by Nisbett et al., note 15.

37 On the many issues of testing for $C T$, see the writings of Ennis cited in his article, note 4, and the article and references in Stephen P. Norris, "Can we test validly for critical thinking?", Educational Researcher 4 (1989), 21-26. See also Peter Facione's The California Critical Thinking Skills Test-College Level (Technical reports and tests), California Academic Press, 1990.

38 For a text that takes seriously the importance of ordering premises for their worthiness of criticism see Francis W, Dauer, Critical Thinking, Oxford, 1989

39 There is a solid and growing body of work on missing assumptions. To mention two: Robert H. Ennis, "Identifying Implicit Assumptions", Synthese 51 (1982), 61-68; and Chapter 6 of Frans H. van Eemeren and Rob Grootendorst's Speech Acts in Argumentative Discussion, Foris, 1984. See also the discussion and references on pp. 185-86 of Ralph H. Johnson and J. Anthony Blair's "Informal Logic: The Past Five Years 1978-1983", American Philosophical Quarterly 22 (1985), 181-96.

40 Richard Herrnstein, "IQ", Atlantic Monthly September 1971. Noam Chomsky, "The Fallacy of Richard Herrnstein's IQ", 285-98; Richard J. Hernstein, "Whatever Happened to Vaudeville?: A Reply to Professor Chomsky", 299-309; Noam Chomsky "Comments on Herrnstein "s Response", 310-24, in N. J. Block and Gerald Dworkin, eds., The IQ Controversy: Critical Readings, Random House-Pantheon Books, 1976.

41 McPeck shows some sympathy for this claim; see p. 89

42 Generalizing the use of Cardinal Newman's phrase, to refer to a move in an argument that destroys any hope for one party to get a fair hearing.

43 If McPeck could show that without value judgments, Ennis's research program should not even get off the ground, his conclusions regarding Ennis's work would be more tolerable. But he hasn't shown this. He makes the correct point in Critical Thinking and Education that "the determination of how much evidence is enough is a direct function of how important it is that a statement be right or wrong." (pp. 54-55) He then argues: "But importance can be 
assessed only in terms of the relative value placed on things by a person or group of persons. Thus the pragmatic dimension of critical thinking cannot be satisfied until one comes to grips with the value system involved in the judgment." (p. 55) But the conclusion only follows if there is no way of controlling for the influence of values, unless one "comes to grips" (examines in detail, I presume) the values. Why should we accept that assumption? Cannot we use large enough random samples, so that dif- ferences of value will be fairly evenly distributed? Or, couldn't we consider matters where we expect that selected individuals or groups will largely agree in their judgments of relative importance?

JONATHAN E. ADLER

DEPARTMENT OF PHILOSOPHY

BROOKLYN COLLEGE, CUNY

BROOKLYN, NY 11210 